\title{
Assessment of Microvascular Function in Children and Adolescents with Diabetes and Obesity
}

\author{
Elna Kochummen ${ }^{1}$, Vatcharapan Umpaichitra ${ }^{1}$, Albara Marwa ${ }^{2}$, Krittika Joshi ${ }^{2}$, Vivian L. Chin ${ }^{1}$ and \\ Sheila Perez-Colon ${ }^{1, *}$ \\ ${ }^{1}$ Department of Pediatrics, Division of Pediatric Endocrinolology, SUNY Downstate Medical Center, New York, United States \\ ${ }^{2}$ Department of Pediatrics, SUNY Downstate Medical Center, New York, United States \\ "Corresponding author: Department of Pediatrics, Division of Pediatric Endocrinolology, SUNY Downstate Medical Center, 445 Lenox Rd., Box 49, Brooklyn, NY 11203, United \\ States. Tel: +1-7186138605, Email: sheilaperez70@hotmail.com
}

Received 2019 January 31; Revised 2019 August 06; Accepted 2019 October 30.

\begin{abstract}
Background: Endothelial dysfunction (ED) is a marker of vascular damage. Glycated hemoglobin (A1C) predicts vascular complications. The EndoPAT (peripheral arterial tonometry) device calculates the reactive hyperemic index (RHI), a measure of endothelial function. The greater the vasodilation, the higher the RHI. We hypothesized that children with poorly-controlled diabetes mellitus (DM) and non-diabetes mellitus (NDM) obese children have ED.

Methods: A cross-sectional study using the EndoPAT device was performed on children with poorly-controlled DM and NDM children. ANOVA, $t$-test, Mann-Whitney U test, multiple linear regression and Spearman correlation were used.

Results: Of 58 children that completed the study (aged $13.1 \pm 3.42$ years), 33 with type 1 diabetes (T1DM), 8 with type 2 diabetes (T2DM) and 17 were NDM obese children. Eighty-five percent were African-American, $60 \%$ were female and 79\% entered puberty. The RHI of children with DM $(1.42 \pm 0.48)$ versus NDM obese group $(1.40 \pm 0.34)$ was not different $(P=0.86)$ regardless of the type of DM or body mass index. In the DM group, for every $1 \%$ increase in latest A1C, the RHI decreased by $0.097(\mathrm{P}=0.01)$ after adjusting for age, gender, and type of DM. The RHI of DM patients with latest A1C of $<10 \%(1.70 \pm 0.58)$ versus those with A1C $\geq 10 \%(1.21 \pm 0.19)$ was statistically different $(\mathrm{P}=0.02)$. In the total study population, males had significantly lower RHI $(1.28 \pm 0.36)$ when compared to females $(1.51 \pm 0.46), \mathrm{P}=0.04$ but this difference disappeared when considering pubertal status and type of diabetes.

Conclusions: Our data showed that patients with poorly-controlled DM as reflected by latest A1C of $\geq 10 \%$ had worse endothelial function as reflected by lower RHI score.
\end{abstract}

Keywords: Endothelial Dysfunction, Reactive Hyperemic Index, Children, Diabetes, Obese

\section{Background}

Endothelial dysfunction (ED) is an early sign of vascular compromise (1) and likely to be present prior to the development of atherosclerosis as it precludes cardiovascular disease (CVD). The major risk factors for CVD are obesity, diabetes, dyslipidemia and elevated blood pressure among others (2). Although CVD is rare in children (3), the risk factors are sometime present since childhood. Moreover, ED was noted in asymptomatic children and young adolescents who had risk factors to develop atherosclerosis without having CVD (4).

Currently, measured glycated hemoglobin (A1C) is the most commonly used and best evaluated marker for glycemic control and vascular complications prediction in diabetic patients (5). The Diabetes Control and Complication Trial (DCCT) Research Group 2000 states that strict glycemic control delays the onset and slows down the progression of diabetic vascular complications (6), which include microvascular (retinopathy, nephropathy, and neuropathy) and macrovascular (cardiac disease, peripheral vascular disease and stroke) diseases (3). Different treatment modalities (4), some aiming for better diabetes control, have shown to reverse the ED. Endothelial function is likely to be reversible in the early process of atherogenesis in children and young adults (4). Through the years, techniques to assess the function of the endothelium have been used clinically and routinely to monitor for CVD in adults, approved by the Food and Drug Administration (FDA). However, as of today, the use of these techniques continues to be part of research studies within the pediatric population. The EndoPAT (peripheral arterial tonometry) is a non-invasive device that measures endothelial function calculated as reactive hyperemic index (RHI). The 
greater the vasodilation, the higher the RHI (7). A Mayo clinic study (8) which compared the EndoPAT results to coronary injection of acetylcholine via cardiac catheterization, concluded that the normal RHI should be $>1.67$. Studies of endothelial function using the EndoPAT device are sparse within the pediatric population and within those, different norms for children have been described. We used an RHI of 1.67 as the cutoff for normal within the pediatric population as other studies have also used $(9,10)$. There are other devices used to evaluate the endothelial function, for example, flow-mediated vasodilation (FMD) measured by ultrasound of the brachial artery, pulse wave velocity (PWV), radial artery tonometry (RAT) and ultrasonographic measurement of common carotid artery intimamedia thickness (CIMT) (11).

\section{Objectives}

In this study, we aimed to assess the endothelial function in children and adolescents with diabetes type 1 (T1DM) and type 2 (T2DM) and in obese non-diabetics (NDM) using the EndoPAT device. We hypothesized that children and adolescents with poorly-controlled T1DM and T2DM as well as NDM obese children have ED reflected by lower RHI.

\section{Methods}

An Institutional Review Board (IRB) approved cross sectional study using the EndoPAT device was performed in children/adolescents with T1DM and T2DM who were poorly-controlled along with overweight/obese children. We enrolled subjects in the age range of 7-21 years from the pediatric endocrinology clinics at SUNY Downstate Medical Center and Kings County Hospital Center, Brooklyn, NY. Written informed consent and assent were obtained from subjects and parents as appropriate. We enrolled 33 T1DM subjects, 8 T2DM subjects and 17 NDM obese subjects. Poorly-controlled DM was defined as A1C $\geq 7.5 \%$ more than 6 months after diagnosis. Subjects with TIDM were treated with insulin and T2DM with metformin alone or combination of metformin and insulin. All NDM overweight/obese subjects were normotensive, (systolic blood pressure [SBP] and diastolic blood pressure [DBP] $<90$ th \% based on age, sex, and height as per National Institutes of Health (NIH) guidelines (12), had normal fasting blood glucose concentrations $(<100 \mathrm{mg} / \mathrm{dL})$, normal A1C $(<5.7 \%)$ and normal fasting lipid profile (total cholesterol $<170 \mathrm{mg} / \mathrm{dL}$, low density lipoprotein cholesterol (LDL) $<110 \mathrm{mg} / \mathrm{dL}$, high density lipoprotein cholesterol (HDL) $>45 \mathrm{mg} / \mathrm{dL}$ and triglyceride (TG) $<90 \mathrm{mg} / \mathrm{dL}$ ) (13). A positive family history of di- abetes, hypertension, hypercholesterolemia or cardiovascular disease was not an exclusion criteria. Mean A1C represents the average value of $\mathrm{AlC}$ within the last year, while latest $\mathrm{A1C}$ is the last $\mathrm{A1C}$ value obtained. This value was obtained within 3 months before the EndoPAT measurements. The following subjects were excluded: T1DM and T2DM with most recent A1C $<7.5 \%$, abnormal renal function (micro-, or macro-albuminuria), retinopathy or neuropathy, presence of hyperlipidemia, pre-hypertension or hypertension, smoking, coronary artery disease, congenital heart disease, carotid artery disease, peripheral vascular diseases, inflammatory or infectious process within the last 3 months, using medications that would affect endothelial function such as oral contraceptive pills or malignancy. Endothelial function was assessed by the same physician with the EndoPAT 2000 after subjects had an overnight fast and within 2 months of the laboratory testing. The EndoPAT device allows non-invasive measurement of endothelial function without the disadvantages of conventional ultrasound measurement. It detects plethysmographic pressure changes in the fingertips caused by the arterial pulse and translates this into a peripheral arterial tone. It is an integrated software program that calculates the RHI automatically between the flow in the arm with reactive hyperemia and the control arm. The subjects lay on a reclining chair with arms supported and hands adjusted at heart level so fingers can freely hang for a minimum of 20 minutes in a quiet, temperature-controlled (72 - 75 degree F) room with dim light.

\subsection{Statistics}

All statistical analyses were performed using the Statistical Package for the Social Sciences (SPSS) for Windows version 16 (IBM Corp., Armonk, NY) and SAS version 9.4 (Cary, NC, USA). Data are reported as mean and standard deviation (mean \pm SD) unless otherwise specify. Statistical procedures used included ANOVA, $t$-test, Mann-Whitney U and Spearman correlation. To estimate RHI predictors, multiple linear regressions with stepwise (backward) elimination for selection of variables were used. A P value of $<0.05$ was considered statistically significant.

\section{Results}

Sixty-nine participants were assessed for enrollment in the study, 11 patients were excluded from the analysis ( $3 \mathrm{pa}$ tients with A1C less than 7.5\%, 3 patients with no EndoPAT device reading obtained, 1 patient with TIDM who developed nephropathy, and 4 patients who developed prediabetes). A total of 58 patients were included for data analysis. Different parameters are described in Table 1 while the 
statistical analysis of groups based on different factors is shown in Table 2.

Among the 58 subjects ( 33 T1DM, 8 T2DM and 17 NDM obese children), 85\% were African American, 60\% female (F) and 79\% pubertal. Mean ( \pm SD) age of all participants was 13.1 years $( \pm 3.42$ ). Age, SBP, DBP, TG, HDL, pubertal status (PS) and RHI were not significantly different among them. There was no statistically significant difference in RHI among subjects in T1DM, T2DM, and NDM obese groups $(\mathrm{P}=0.79)$. Within the T1DM group, the RHI was not statistically different between those who were obese and those with normal weight $(\mathrm{P}=0.40)$. The RHI between T1DM and T2DM groups were $1.4 \pm 0.5$ and $1.5 \pm 0.5(\mathrm{P}=0.50)$, respectively. The RHI between T2DM and NDM obese group were $1.5 \pm 0.5$ and $1.4 \pm 0.3(\mathrm{P}=0.47)$, respectively. There was no difference between latest A1C among T1DM and T2DM groups, $\mathrm{P}=0.29$, and between the mean $\mathrm{A} 1 \mathrm{C}$ amongst T1DM and T2DM, $\mathrm{P}=0.27$.

The mean RHI of the DM group (n: $41,1.42 \pm 0.48$ ) versus the NDM obese group (n: 17, $1.40 \pm 0.34$ ) was similar (P: 0.86) regardless of type of diabetes or body mass index (BMI). No statistical difference in RHI was noted between African American and Hispanic subjects (1.45 \pm 0.46 vs. 1.16 $\pm 0.15, \mathrm{P}=0.08)$. Males $(\mathrm{M})$ had statistically significant lower RHI (1.28 \pm 0.36$)$ compared to F $(1.51 \pm 0.46)$, P: 0.04 but after adjusting for PS, the difference was not seen (P: 0.11). Subgroup analysis after adjusting for PS showed the difference persisted in the NDM group $(\mathrm{P}<0.01)$ and no difference in RHI was seen between $\mathrm{M}$ and $\mathrm{F}$ within the DM group (P: 0.36). There was no statistically significant difference in RHI between pre-pubertal and pubertal children overall $(\mathrm{P}=0.08)$. There was a statistically significant difference in RHI of the DM (T1 and T2) group with latest $\mathrm{A} 1 \mathrm{C}<$ 10 (n: $18,1.70 \pm 0.58)$ compared to those with $\mathrm{A1C} \geq 10$ (n: $23,1.21 \pm 0.19), \mathrm{P}:<0.01$. For every $1 \%$ increase in latest A1C, the RHI decreased by 0.097 (P: 0.01) adjusted for age, sex, and type of DM. No statistically significant difference was noted in mean $\mathrm{A} 1 \mathrm{C}$ for those with $\mathrm{A} 1 \mathrm{C}<10$ vs. those with $A 1 C \geq 10, P: 0.09$. There was negative correlation between RHI and latest $\mathrm{A} 1 \mathrm{C}$ in the diabetic group, $\mathrm{r}=-0.932, \mathrm{P}: 0.01$, while no correlation was noted with the mean A1C and RHI, $\mathrm{r}=-0.1, \mathrm{P}: 0.34$. Amongst patients with diabetes, there was no significant correlation between years of diabetes since diagnosis and $\mathrm{RHI}(\mathrm{r}=-0.74, \mathrm{P}=0.64)$ ). After controlling for pubertal status, no statistically significant association was noted between RHI and age, $\mathrm{P}=0.30$ ).

\section{Discussion}

Our study used the Endopat device to evaluate the endothelial function in T1DM, T2DM and NDM obese children and adolescents. Previous studies done in children and adolescents with diabetes are mainly in T1DM patients (7, 10, 14-17). Prospective studies with the EndoPAT on T1DM adolescents revealed the presence of endothelial dysfunction in 76.7\% (7), and a negative correlation between endothelial function and $\mathrm{A} 1 \mathrm{C}$ (10). In our study, latest $\mathrm{A} 1 \mathrm{C}$ (within 3 months prior to the use of the EndoPat) was an important predictor of endothelial function. Those who had higher A1C had worse endothelial function. Furthermore, diabetic patients with A1C values of $10 \%$ or above had statistically significant lower RHI in comparison to those with $\mathrm{A} 1 \mathrm{C}$ values below $10 \%$. Well-established norms for RHI in children and adolescents as well as long-term studies identifying the cut off A1C values where ED would develop or would be reversed are definitely needed.

Studies have shown that children with T1DM had significant ED when compared with non-diabetics $(16,17)$. Another study using the EndoPat demonstrated significantly lower RHI scores in obese adolescents when compared to lean controls (18). Krantz et al. demonstrated that the mean CIMT was greater in adolescents with T1DM when compared with controls (19). Bruzzi et al. demonstrated impaired FMD in T1DM children when compared with healthy controls (14). Ciftel et al. compared children with T1DM without complications and healthy children (15). Their study demonstrated ED (using FMD and CIMT methods) and increased arterial stiffness (using PWV) in the T1DM group (15). The SEARCH study compared the endothelial function in young patients with T1DM and T2DM using FMD, PWV and RAT, and concluded that youth with T2DM have worse arterial stiffness when compared with T1DM $(\mathrm{P}<0.01)(20)$. In our study, we included T1DM and T2DM patients to assess if the type of diabetes influences endothelial dysfunction. Surprisingly, the arterial stiffness assessed by EndoPAT among patients with T1DM and T2DM were not significantly different. While the T1DM group had slightly higher A1C levels, there were not statistically different. Subjects with T1DM had more years of disease compared to those with T2DM although not able to reach statistical significance. Despite this, the endothelial dysfunction among these groups was similar. These findings are likely to the fact that in patients with T2DM, ED precedes overt hyperglycemia (21) by several years $(2,22)$, rather than caused by it. Hyperinsulinemia, insulin resistance and obesity are all factors affecting the endothelium in T2DM patients even before the disease is diagnosed. Conversely, ED in patients with T1DM develops after period of hyperglycemia.

In the Framingham Heart Study in adults, a significant inverse relation was demonstrated between endothelial function (determined by EndoPAT) and multiple cardiovascular risk factors such as male sex, BMI, total/HDL cholesterol, DM, smoking, and lipid-lowering treatment (23). Bruzzi et al. (14) did not find significant correla- 


\begin{tabular}{|c|c|c|c|c|}
\hline & T1DM & T2DM & NDM & P Value \\
\hline Age, $y$ & $12.7 \pm 3.8$ & $15 \pm 2.20$ & $12.8 \pm 2.7$ & 0.07 \\
\hline BMI, $\mathrm{kg} / \mathrm{m}^{2}$ & $20.8 \pm 4.5$ & $31.6 \pm 8.3$ & $34.1 \pm 6.7$ & 0.02 \\
\hline BMI Z-score & $0.4 \pm 0.9$ & $1.7 \pm 0.9$ & $2.3 \pm 0.3$ & 0.02 \\
\hline SBP, mmHg & $108.6 \pm 9.7$ & $116.8 \pm 9.8$ & $112.1 \pm 10$ & 0.87 \\
\hline DBP, mmHg & $63.9 \pm 8.2$ & $69.1 \pm 6.9$ & $65 \pm 7.5$ & 0.92 \\
\hline Total cholesterol, mg/dL & $157.6 \pm 33.3$ & $150.1 \pm 43.2$ & $149.4 \pm 18.2$ & $<0.01$ \\
\hline $\mathrm{TG}, \mathrm{mg} / \mathrm{dL}$ & $91.1 \pm 42.4$ & $90.6 \pm 44.2$ & $82.5 \pm 36.4$ & 0.82 \\
\hline HDL, mg/dL & $55.9 \pm 12.6$ & $47 \pm 13.8$ & $43.3 \pm 10.5$ & 0.32 \\
\hline LDL, $\mathbf{m g} / \mathbf{d L}$ & $82 \pm 26.1$ & $85.2 \pm 31.1$ & $89.5 \pm 18.8$ & 0.03 \\
\hline Years diagnosed & $5.74 \pm 4.40$ & $2.53 \pm 1.91$ & N/A & 0.05 \\
\hline Mean A1C, \% & $10.5 \pm 1.9$ & $9.7 \pm 1.8$ & $5.3 \pm 0.3$ & $<0.01$ \\
\hline Latest A1C, \% & $10.8 \pm 2.0$ & $9.9 \pm 1.7$ & $5.2 \pm 0.3$ & $<0.01$ \\
\hline RHI & $1.4 \pm 0.5$ & $1.5 \pm 0.5$ & $1.4 \pm 0.3$ & 0.79 \\
\hline
\end{tabular}

tion between diabetes duration and FMD. Similarly, we did not find significant correlation of diabetes duration with RHI using the EndoPAT device. Of note, the EndoPAT device evaluates endothelial function in the microvasculature while the FMD evaluates such function in larger vessels. Selamet Tierney et al. (24) tested prospectively the reproducibility and feasibility of the EndoPAT and concluded that in healthy adolescents, EndoPAT is feasible, has excellent reproducibility, and provides an easy and reliable means of assessing endothelial function in the pediatric population.

In our study, the endothelial function as reflected by RHI was not statistically different when comparing diabetic patients (T1 and T2) with the NDM obese patients, even when taking type of diabetes and BMI into account. Both groups had a lower RHI score below 1.67 suggesting that each risk factor (diabetes or obesity) have a negative effect on the endothelium. A previous study done by Wadwa et al. (20) suggested that the difference in arterial stiffness between patients with T1DM and T2DM could have been due to elevated blood pressure and central adiposity. In our study, all subjects involved were normotensive at the time of the test though central adiposity was not measured.

As reported by Bhangoo et al., RHI increases during puberty in males as well as females. Endothelial function appears to improve during puberty as a result of hormonal changes, estrogen and DHEAS (25). Bruzzi et al. (14) reported that females had better endothelial function when compared to males in children and adolescents with T1DM. In our study, females had higher RHI score implicating better endothelial function when compared to males in the NDM obese group despite controlling for pubertal status. However, the difference was not sustained within the diabetes groups, T1DM and T2DM.

There have been conflicting data in regards to endothelial function in obese children. Landgraf et al. (26) and Mahmud et al. (27), reported lower RHI in obese children when compared with lean children. However, Tryggestad et al. (28) did not find such difference. In our study, no significant changes in the RHI were noted when the obese and T2DM patients were compared while controlling for BMI or glycemic control.

Our study has limitations. Despite being representative of our population, our sample size was small and unevenly distributed. Our study did not include non-diabetic lean subjects due to difficulty recruiting. Therefore, the findings should be interpreted with caution and further larger studies are needed. Nevertheless, our study provided relevant preliminary information for further studies regarding endothelial function in children.

\subsection{Conclusions}

Our data showed that patients with poorly-controlled DM as reflected by latest A1C of $10 \%$ or more had worse endothelial function as reflected by lower RHI score. Longitudinal studies are needed to elucidate the significance and implications, if any, of these findings. Assessment of endothelial function using EndoPAT device may be useful as 


\begin{tabular}{|c|c|c|c|}
\hline Group & $\mathbf{N}$ & RHI $($ Mean \pm SD $)$ & PValue \\
\hline DM & & & 0.86 \\
\hline $\mathrm{T} 1$ and $\mathrm{T} 2$ & 41 & $1.42 \pm 0.48$ & \\
\hline NDM & 17 & $1.40 \pm 0.34$ & \\
\hline Ethnicity & & & 0.08 \\
\hline African American & 49 & $1.45 \pm 0.46$ & \\
\hline Hispanics & 7 & $1.16 \pm 0.15$ & \\
\hline Not reported & 2 & & \\
\hline \multicolumn{4}{|l|}{ Gender } \\
\hline Among all subjects & & & 0.04 \\
\hline Males & 23 & $1.28 \pm 0.36$ & \\
\hline Females & 34 & $1.51 \pm 0.46$ & \\
\hline Among NDM group & & & $<0.01$ \\
\hline Males & 8 & $1.17 \pm 0.19$ & \\
\hline Females & 9 & $1.61 \pm 0.30$ & \\
\hline Among DM group & & & 0.36 \\
\hline Males & 16 & $1.34 \pm 0.42$ & \\
\hline Females & 25 & $1.48 \pm 0.51$ & \\
\hline Puberty status & & & 0.08 \\
\hline Non-pubertal & 12 & $1.25 \pm 0.34$ & \\
\hline Pubertal & 45 & $1.46 \pm 0.46$ & \\
\hline Latest A1C & & & $<0.01$ \\
\hline $\mathrm{A} 1 \mathrm{C}<10$ & 18 & $1.70 \pm 0.58$ & \\
\hline $\mathrm{A} 1 \mathrm{C} \geq 10$ & 23 & $1.21 \pm 0.19$ & \\
\hline Mean A1C & & & 0.09 \\
\hline $\mathrm{A} 1 \mathrm{C}<10$ & 19 & $1.55 \pm 0.54$ & \\
\hline $\mathrm{A} 1 \mathrm{C} \geq 10$ & 22 & $1.31 \pm 0.38$ & \\
\hline
\end{tabular}

Abbreviations: A1C, glycated hemoglobin; DM, diabetes mellitus; NDM, nondiabetes mellitus (obese); RHI, reactive hyperemia index

part of routine care for DM and NDM obese children and adolescents.

\section{Acknowledgments}

We are grateful to Dr. Madu Rao, Dr. Stephen Wadowski and Dr. Simon Rabinowitz, Department of Pediatrics at SUNY Downstate Medical Center, Brooklyn, NY for their support.

\section{Footnotes}

Authors' Contribution: All authors are responsible for reported research. All authors have participated in the con- cept and designs; analysis and interpretation of data; drafting or revising the manuscript, and they have approved the manuscript as submitted.

Conflict of Interests: All authors report no conflict of interest.

Ethical Approval: This study was approved by the IRB at SUNY Downstate Medical Center, Brooklyn, NY Institutional Review Board. SUNY Downstate Medical Center IRB Office, project \#868043-5.

Funding/Support: Funding for this study was provided in part by the Madu Rao Foundation and by the Department of Pediatrics at SUNY Downstate Medical Center.

Informed Consent: Written informed consent and assent were obtained from subjects and parents as appropriate.

\section{References}

1. Paneni F, Beckman JA, Creager MA, Cosentino F. Diabetes and vascular disease: pathophysiology, clinical consequences, and medical therapy: Part I. Eur Heart J. 2013;34(31):2436-43. doi: 10.1093/eurheartj/eht149. [PubMed: 23641007]. [PubMed Central: PMC3743069].

2. Sena CM, Pereira AM, Seica R. Endothelial dysfunction - a major mediator of diabetic vascular disease. Biochim Biophys Acta. 2013;1832(12):2216-31. doi: 10.1016/j.bbadis.2013.08.006. [PubMed: 23994612].

3. Donaghue KC, Chiarelli F, Trotta D, Allgrove J, Dahl-Jorgensen K. Microvascular and macrovascular complications associated with diabetes in children and adolescents. Pediatr Diabetes. 2009;10 Suppl 12:195-203. doi: 10.1111/j.1399-5448.2009.00576.x. [PubMed: 19754630].

4. Celermajer DS. Endothelial dysfunction: Does it matter? Is it reversible? J Am Coll Cardiol. 1997;30(2):325-33. doi: 10.1016/s07351097(97)00189-7. [PubMed: 9247501].

5. Sacks DB, Arnold M, Bakris GL, Bruns DE, Horvath AR, Kirkman MS, et al. Guidelines and recommendations for laboratory analysis in the diagnosis and management of diabetes mellitus. Clin Chem. 2011;57(6):e1-e47. doi: 10.1373/clinchem.2010.161596. [PubMed: 21617152].

6. Nathan DM, Lachin J, Cleary P, Orchard T, Brillon DJ, Backlund JY, et al. Intensive diabetes therapy and carotid intima-media thickness in type 1 diabetes mellitus. N Engl J Med. 2003;348(23):2294-303. doi: 10.1056/NEJMoa022314. [PubMed: 12788993]. [PubMed Central: PMC2701300].

7. Scaramuzza AE, Redaelli F, Giani E, Macedoni M, Giudici V, Gazzarri A, et al. Adolescents and young adults with type 1 diabetes display a high prevalence of endothelial dysfunction. Acta Paediatr. 2015;104(2):1927. doi: 10.1111/apa.12877. [PubMed: 25424745].

8. Bonetti PO, Pumper GM, Higano ST, Holmes DJ, Kuvin JT, Lerman A. Noninvasive identification of patients with early coronary atherosclerosis by assessment of digital reactive hyperemia.J Am Coll Cardiol. 2004;44(11):2137-41. doi: 10.1016/j.jacc.2004.08.062. [PubMed: 15582310].

9. Butbul Aviel Y, Dafna L, Pilar G, Brik R. Endothelial function in children with a history of henoch schonlein purpura. Pediatr Rheumatol Online J. 2017;15(1):3. doi: 10.1186/s12969-016-0135-z. [PubMed: 28088210]. [PubMed Central: PMC5237555].

10. Shachor-Meyouhas Y, Pillar G, Shehadeh N. Uncontrolled type 1 diabetes mellitus and endothelial dysfunction in adolescents. Isr Med Assoc J. 2007;9(9):637-40. [PubMed: 17939622].

11. Arrebola-Moreno AL, Laclaustra M, Kaski JC. Noninvasive assessment of endothelial function in clinical practice. Rev Esp Cardiol 
(Engl Ed). 2012;65(1):80-90. doi: 10.1016/j.recesp.2011.09.012. [PubMed: 22099430].

12. National High Blood Pressure Education Program Working Group on High Blood Pressure in C Adolescents. The fourth report on the diagnosis, evaluation, and treatment of high blood pressure in children and adolescents. Pediatrics. 2004;114(2):555-76. doi: 10.1542/peds.114.2.S2.555.

13. Expert Panel on Integrated Guidelines for Cardiovascular Health; Risk Reduction in Children Adolescents National Heart Lung Blood Institute. Expert panel on integrated guidelines for cardiovascular health and risk reduction in children and adolescents: summary report. Pediatrics. 2011;128 Suppl 5:S213-56. doi: 10.1542/peds.20092107C. [PubMed: 22084329]. [PubMed Central: PMC4536582].

14. Bruzzi P, Predieri B, Patianna VD, Salvini A, Rossi R, Modena MG, et al. Longitudinal evaluation of endothelial function in children and adolescents with type 1 diabetes mellitus: A long-term follow-up study. Pediatr Int. 2014;56(2):188-95. doi: 10.1111/ped.12220. [PubMed: 24020908].

15. Ciftel M, Ertug H, Parlak M, Akcurin G, Kardelen F. Investigation of endothelial dysfunction and arterial stiffness in children with type $1 \mathrm{di}-$ abetes mellitus and the association with diastolic dysfunction. Diab Vasc Dis Res. 2014;11(1):19-25. doi: 10.1177/1479164113508564. [PubMed: 24169808].

16. Haller MJ, Stein J, Shuster J, Theriaque D, Silverstein J, Schatz DA, et al. Peripheral artery tonometry demonstrates altered endothelial function in children with type 1 diabetes. Pediatr Diabetes. 2007;8(4):193-8. doi: 10.1111/j.1399-5448.2007.00246.x. [PubMed: 17659060].

17. Pareyn A, Allegaert K, Asscherickx W, Peirsman E, Verhamme P, Casteels K. Impaired endothelial function in female adolescents with type 1 diabetes measured by peripheral artery tonometry. Eur J Pediatr. 2013;172(8):1017-22. doi: 10.1007/s00431-013-1988-5. [PubMed: 23525544].

18. Agarwal C, Cohen HW, Muzumdar RH, Heptulla RA, Renukuntla VS, Crandall J. Obesity, hyperglycemia and endothelial function in inner city Bronx adolescents: A cross-sectional study. IntJ Pediatr Endocrinol. 2013;2013(1):18. doi: 10.1186/1687-9856-2013-18. [PubMed: 24164965]. [PubMed Central: PMC3816548].

19. Krantz JS, Mack WJ, Hodis HN, Liu CR, Liu CH, Kaufman FR. Early onset of subclinical atherosclerosis in young persons with type 1 diabetes. Pediatr.2004;145(4):452-7. doi:10.1016/j.jpeds.2004.06.042. [PubMed:
15480366]

20. Wadwa RP, Urbina EM, Anderson AM, Hamman RF, Dolan LM, Rodriguez BL, et al. Measures of arterial stiffness in youth with type 1 and type 2 diabetes: the SEARCH for diabetes in youth study. Diabetes Care. 2010;33(4):881-6. doi: 10.2337/dc09-0747. [PubMed: 20067960]. [PubMed Central: PMC2845046].

21. Schalkwijk CG, Stehouwer CD. Vascular complications in diabetes mellitus: The role of endothelial dysfunction. Clin Sci (Lond). 2005;109(2):143-59. doi: 10.1042/CS20050025. [PubMed: 16033329].

22. Highlander P, Shaw GP. Current pharmacotherapeutic concepts for the treatment of cardiovascular disease in diabetics. Ther Adv Cardiovasc Dis. 2010;4(1):43-54. doi: 10.1177/1753944709354305. [PubMed: 19965897].

23. Hamburg NM, Keyes MJ, Larson MG, Vasan RS, Schnabel R, Pryde $\mathrm{MM}$, et al. Cross-sectional relations of digital vascular function to cardiovascular risk factors in the Framingham Heart Study. Circulation. 2008;117(19):2467-74. doi: 10.1161/CIRCULATIONAHA.107.748574. [PubMed: 18458169]. [PubMed Central: PMC2734141].

24. Selamet Tierney ES, Newburger JW, Gauvreau K, Geva J, Coogan E, Colan SD, et al. Endothelial pulse amplitude testing: Feasibility and reproducibility in adolescents. J Pediatr. 2009;154(6):901-5. doi: 10.1016/j.jpeds.2008.12.028. [PubMed: 19217124].

25. Bhangoo A, Sinha S, Rosenbaum M, Shelov S, Ten S. Endothelial function as measured by peripheral arterial tonometry increases during pubertal advancement. Horm Res Paediatr. 2011;76(4):22633. doi: 10.1159/000328455. [PubMed: 21778688]. [PubMed Central: PMC3224510].

26. Landgraf K, Friebe D, Ullrich T, Kratzsch J, Dittrich K, Herberth G, et al. Chemerin as a mediator between obesity and vascular inflammation in children. J Clin Endocrinol Metab. 2012;97(4):E556-64. doi: 10.1210/jc.2011-2937. [PubMed: 22438234].

27. Mahmud FH, Hill DJ, Cuerden MS, Clarson CL. Impaired vascular function in obese adolescents with insulin resistance. $J$ Pediatr. 2009;155(5):678-82. doi: 10.1016/j.jpeds.2009.04.060. [PubMed: 19595374].

28. Tryggestad JB, Thompson DM, Copeland KC, Short KR. Obese children have higher arterial elasticity without a difference in endothelial function: The role of body composition. Obesity (Silver Spring). 2012;20(1):165-71. doi: 10.1038/oby.2011.309. [PubMed: 21996664]. 